\title{
Hemodynamic Abnormalities in Response to Supine Exercise in Patients After Operative Correction of Tetrad of Fallot After Early Childhood
}

ALBERT P. ROCCHINI, MD

Ann Arbor, Michigan

From the C. S. Mott Children's Hospital, Department of Pediatrics, Section of Pediatric Cardiology. University of Michigan Medical Center, Ann Arbor, Michigan. Manuscript received December 11, 1980; revised manuscript received March 23, 1981, accepted March 31. 1981.

Address for reprints: Albert P. Rocchini, MD, C. S. Mott Children's Hospital, Department of Pediatrics, F1115 Box 66, Ann Arbor, Michigan 48109.
The exercise hemodynamic values in two groups of patlents with repaired tetrad of Fallot (eight patients with some residual pulmonary insufficiency and seven patients without insufficiency) were compared with values in seven patients with trivial pulmonary stenosis who had not been operated on. The patients with tetrad of Fallot underwent surgery after age 8 years and all had a good hemodynamlc repair (no shunts and a right ventricular systolic pressure at rest of less than $60 \mathrm{~mm} \mathrm{Hg}$ ). Exercise increased the right ventricular outflow tract gradient by the same magnitude in all three groups of patients. However, both surgically treated groups experienced impaired cardiac pump function on suplne exercise (that Is, a lower than anticlpated cardiac index for the amount of oxygen consumed and a signiflcant decrease in stroke index). Exercise also caused both groups with repair to have a decrease in stroke index and a concomitant increase in right ventricular end-diastollc and pulmonary wedge pressures; in contrast, the patients with pulmonary arterial stenosis had an Increase in stroke index and a concomitant decrease in right ventricular end-dlastollc and pulmonary wedge pressures.

These findings Indicate that an impaired cardiac response to supine exercise can occur in patients in whom Intracardlac repair of tetrad of Fallot was performed after early chlldhood, even though they have had a good hemodynamic repair. In addition, the impaired cardiac response to supine exercise in these patlents was probably due largely to an altered myocardial compliance rather than to elther residual pulmonary stenosis or pulmonary insufficiency.

Limited information is available concerning the hemodynamic response to exercise after the surgical repair of tetralogy of Fallot. ${ }^{1-6}$ Epstein et al. ${ }^{1}$ demonstrated that the overall cardiovascular response to upright exercise was impaired in 9 of 10 postoperative patients with tetrad of Fallot. They observed that four of six patients had a significant pulmonary outflow tract gradient with exercise despite a trivial gradient at rest. These data suggest that part of the abnormal cardiovascular response to exercise in patients with a good surgical repair of tetrad of Fallot may be due to the development of significant right ventricular outflow tract obstruction with exercise. However, other factors such as a large residual intracardiac shunt, ${ }^{7}$ severe residual pulmonary stenosis, ${ }^{7}$ residual pulmonary insufficiency ${ }^{5}$ or left ventricular dysfunction ${ }^{8}$ may also contribute to an abnormal exercise response in patients with repaired tetrad of Fallot.

The purpose of this study was to determine if residual pulmonary insufficiency or right ventricular outflow tract obstruction, or both, causes the impaired hemodynamic response to exercise observed in some patients who have had a good intracardiac repair of tetrad of Fallot. 


\section{Methods}

Study patients: Fifteen patients aged 10 to 26 years underwent cardiac catheterization 1 to 12 years after surgical repair of tetrad of Fallot (Table I). Seven of these patients had a Dacron conduit with a porcine aortic valve (Hancock Laboratories, Anaheim, California) used to establish continuity between the right ventricle and pulmonary artery. These patients also had ligation of either a previous systemic to pulmonary shunt or collateral vessels. The remaining eight patients with repair had the right ventricular outflow tract reconstructed with a patch that extended across the pulmonary valve anulus (Table I). All 15 patients with tetrad of Fallot underwent surgical repair after age 8 years and had a good hemodynamic repair (that is, no intracardiac shunts and a right ventricular pressure at rest of less than $60 \mathrm{~mm} \mathrm{Hg}$ ) (Table I).

All 15 postoperative patients were asymptomatic, had a grade $3 / 6$ systolic ejection type murmur at the left sternal border, mild cardiomegaly on chest X-ray film and right bundle branch block on electrocardiography. No patient with a conduit had a murmur of pulmonary insufficiency whereas all eight of the patients with a patched outflow tract had a grade $3 / 4$ diastolic murmur of moderate pulmonary insufficiency. Graded treadmill exercise testing was performed before cardiac catheterization in all patients using the Bruce protocol..$^{9}$
Cardiac catheterization: Each patient underwent routine diagnostic right and left heart catheterization in the supine position. A 7 French thermodilution catheter and a 5 French Swan-Ganz catheter were introduced percutaneously into the right femoral vein and a 7 French pigtail catheter was inserted percutaneously into the right femoral artery. Oxygen consumption was directly measured utilizing Douglas bags and a Tissot spirometer. Cardiac output at rest was measured utilizing thermodilution in all patients without pulmonary insufficiency. In the eight patients with pulmonary insufficiency cardiac output was calculated utilizing the Fick principle. All patients then underwent submaximal exercise in the supine position utilizing a variable resistance bicycle ergometer at a work load designed to raise the heart rate to between 140 and 180 beats/min. After a steady state of exercise had been achieved for 4 to 5 minutes, cardiac output was measured in all patients.

Hemodynamic measurements at rest and during exercise: The following variables were measured at rest and during exercise: cardiac index, heart rate, oxygen consumption, stroke index, pulmonary arterial wedge pressure, right ventricular systolic and end-diastolic pressures and pulmonary arterial and aortic oxygen saturation values. For the two groups of patients with repaired tetrad of Fallot, the mean values for each of these hemodynamic variables were calculated and compared with each other and with the mean values

TABLE I

Pertinent Clinical and Hemodynamic Findings at Rest in 15 Patlents Whth Postoperative Tetrad of Fallot

\begin{tabular}{|c|c|c|c|c|c|c|c|}
\hline \multirow[b]{2}{*}{ Case } & \multirow[b]{2}{*}{ Diagnosis } & \multirow{2}{*}{$\begin{array}{l}\text { Age at } \\
\text { Op (yr) }\end{array}$} & \multirow{2}{*}{$\begin{array}{l}\text { Years } \\
\text { Postop }\end{array}$} & \multirow{2}{*}{$\begin{array}{c}\text { Type of } \\
\text { Reconstruction }\end{array}$} & \multirow[b]{2}{*}{ Symptoms } & \multicolumn{2}{|c|}{$\begin{array}{l}\text { Pressures at } \\
\text { Rest }(\mathrm{mm} \mathrm{Hg})\end{array}$} \\
\hline & & & & & & RV & $\Delta \mathrm{PS}$ \\
\hline \multicolumn{8}{|c|}{ Group I-No Residual Pulmonary Regurgitation } \\
\hline 1 & $\begin{array}{l}\text { Acquired pulm atresia, VSD, left B-T } \\
\text { shunt }\end{array}$ & 15 & 2 & $\begin{array}{l}25 \mathrm{~mm} \text { RV-PA } \\
\text { conduit }\end{array}$ & None & $55 / 4$ & 37 \\
\hline 2 & Pulm atresia, VSD, collat & 25 & 1 & $\begin{array}{l}25 \text { mm RV-PA } \\
\text { conduit }\end{array}$ & None & $20 / 4$ & 2 \\
\hline 3 & $\begin{array}{l}\text { Acquired puim atresia, VSD, right } \\
\text { B-T shunt }\end{array}$ & 17 & 2 & $\begin{array}{l}25 \text { mm RV-PA } \\
\text { conduit }\end{array}$ & None & $40 / 6$ & 20 \\
\hline 4 & Pulm atresia, VSD, right B-T shunt & 13 & 2 & $\begin{array}{l}20 \mathrm{~mm} \text { RV-PA } \\
\text { conduit }\end{array}$ & None & $46 / 7$ & 16 \\
\hline 5 & Pulm atresia, VSD, right B-T shunt & 10 & 1 & 20 mm RV-PA & None & $52 / 5$ & 30 \\
\hline 6 & $\begin{array}{l}\text { Pulm atresia, VSD, right + left B-T } \\
\text { shunt }\end{array}$ & 15 & 3 & 22 mm RV-PA & None & $52 / 6$ & 30 \\
\hline 7 & Pulm atresia, VSD, collat & 13 & 2 & $\begin{array}{l}22 \mathrm{~mm} \text { RV-PA } \\
\text { conduit }\end{array}$ & None & $46 / 9$ & 20 \\
\hline \multicolumn{8}{|c|}{ Group II-Moderate Residual Pulmonary Regurgitation } \\
\hline 8 & ToF, right B-T shunt & 12 & 2 & $\begin{array}{l}\text { RV-PA outflow } \\
\text { patch }\end{array}$ & None & $55 / 11$ & 35 \\
\hline 9 & ToF, left B-T shunt & 14 & 2 & $\begin{array}{l}\text { RV-PA outflow } \\
\text { patch }\end{array}$ & None & $42 / 6$ & 20 \\
\hline 10 & ToF, Waterston shunt & 14 & 1 & $\begin{array}{l}\text { RV-PA outflow } \\
\text { patch }\end{array}$ & None & $30 / 5$ & 10 \\
\hline 11 & ToF, left B-T shunt & 8.5 & 12 & $\begin{array}{l}\text { RV-PA outflow } \\
\text { patch }\end{array}$ & None & $50 / 8$ & 15 \\
\hline 12 & ToF, left and right B-T shunt & 16 & 2 & $\begin{array}{l}\text { RV-PA outfiow } \\
\text { pátch }\end{array}$ & None & $45 / 8$ & 15 \\
\hline 13 & ToF, right B-T shunt & 9 & 3 & $\begin{array}{l}\text { RV-PA outflow } \\
\text { patch }\end{array}$ & None & $42 / 8$ & 10 \\
\hline 14 & ToF, right B-T shunt & 9 & 8 & $\begin{array}{l}\text { RV-PA outflow } \\
\text { patch }\end{array}$ & None & $52 / 12$ & 9 \\
\hline 15 & ToF, right B-T shunt & 12 & 2 & $\begin{array}{l}\text { RV-PA outflow } \\
\text { patch }\end{array}$ & None & $50 / 7$ & 22 \\
\hline
\end{tabular}

$\mathrm{B}-\mathrm{T}=$ Blalock-Taussig; collat $=$ collateral vessels; $\mathrm{Op}=$ operation; $\mathrm{PA}=$ pulmonary artery; Postop = postoperative; pulm = pulmonary; $\Delta \mathrm{PS}$ $=$ pulmonary stenosis gradient; RV = right ventricular; ToF = tetrad of Fallot; VSD = ventricular septal defect. 
obtained in seven nonsurgically treated patients with trivial pulmonary stenosis matched for body surface area, sex and right ventricular outflow tract gradient. In addition, the relation between the change in oxygen consumption and cardiac index for both groups of patients with repair was compared with this relation in patients with mild pulmonary stenosis and patients without heart disease. ${ }^{10}$ Left ventricular ejection fraction was calculated using the area-length method described by Dodge et al. ${ }^{11}$

Statistical analyses were performed using a univariate one way analysis of variance and the Scheffe procedure for multiple comparisons. ${ }^{12}$ All values are presented as a mean \pm standard deviation.

\section{Results}

Graded treadmill exercise testing: Decreased exercise endurance was observed in both groups of patients with repaired tetrad of Fallot. These patients exercised for 10 to 14 minutes (10th to 35 th percentile for age) compared with 12 to 18 minutes (25th to 95 th percentile for age) for the patients with mild pulmonary stenosis. Six patients with repair had premature ventricular complexes (unifocal in four, multifocal in one and couplets in one) (Lown grades II to IVA) ${ }^{13}$ with treadmill exercise, whereas no patient with pulmonary stenosis experienced arrhythmia with treadmill exercise ( $p<0.001$ ). No treadmill exercise test was terminated because of arrhythmia. Neither treadmill exerciseinduced arrhythmia nor exercise endurance differed significantly in the patients with repair who did or did not have pulmonary regurgitation.

Supine exercise during catheterization: ventricular arrhythmia: No residual intracardiac shunt was demonstrated at postoperative cardiac catheterization in any of the patients with repaired tetrad of Fallot (by oxygen saturation data and left ventricular angiography). No significant difference was present among any of the three groups with respect to heart rate or oxygen consumption either at rest or during exercise. Thus, the resting and exercise states were comparable among the three groups (Table II). In addition, despite the development of ventricular arrhythmia with treadmill exercise in six of the patients with repair, no significant arrhythmia developed during submaximal supine exercise in any of the three patient groups.

Cardiac index during exercise: On exercise the right ventricular systolic pressure and right ventricular

\section{TABLE \|}

Comparison of the Hemodynamic Findings in the Three Groups of Patients

\begin{tabular}{|c|c|c|c|c|c|c|c|c|c|c|c|}
\hline Group & $\mathbf{H R}$ & $\mathrm{VO}_{2}$ & $\begin{array}{l}\text { RVEDP } \\
(\mathrm{mm} \mathrm{Hg})\end{array}$ & $\begin{array}{c}\text { RVP } \\
(\mathrm{mm} \mathrm{Hg})\end{array}$ & $\begin{array}{c}\Delta \mathrm{PS} \\
(\mathrm{mm} \mathrm{Hg})\end{array}$ & $\mathrm{Cl}$ & SI & PaWP & $\begin{array}{c}\mathrm{PaO}_{2} \\
\mathrm{Sat}\end{array}$ & 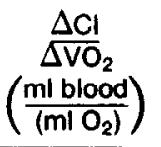 & LVEF \\
\hline \multicolumn{12}{|l|}{$\begin{array}{l}\text { I: ToF, } \\
\text { no PI } \\
(n=7)\end{array}$} \\
\hline $\begin{array}{l}\text { Rest } \\
\text { Ex }\end{array}$ & $\begin{array}{c}81 \\
\pm 7 \\
159 \\
\pm 9\end{array}$ & $\begin{array}{c}128 \\
\pm 9 \\
784 \\
\pm 168^{*}\end{array}$ & $\begin{array}{l}5 \\
\pm 1 \\
12 \\
\pm 3\end{array}$ & $\begin{array}{l}43 \\
\pm 14 \\
73 \\
\pm 17\end{array}$ & $\begin{array}{l}21 \\
\pm 13 \\
44 \\
\pm 17^{*}\end{array}$ & $\begin{array}{l}3.5 \\
\pm 0.7 \\
5.9 \\
\pm 1.1^{*}\end{array}$ & $\begin{array}{l}45 \\
\pm 6 \\
40 \\
\pm 6^{\circ}\end{array}$ & $\begin{array}{c}7 \\
14 \\
\pm 4^{*}\end{array}$ & $\begin{array}{l}68 \\
\pm 5 \\
35 \\
\pm 6\end{array}$ & $\begin{array}{l}- \\
4_{ \pm 0.5}\end{array}$ & $\begin{array}{l}64 \\
\pm 7 \\
-\end{array}$ \\
\hline \multicolumn{12}{|c|}{$\begin{array}{l}\text { II: ToF, } \\
\text { PI } \\
(n=8)\end{array}$} \\
\hline Rest & $\begin{array}{c}81 \\
\pm 8 \\
153 \\
\pm 8\end{array}$ & $\begin{array}{c}136 \\
\pm 22 \\
788 \\
\pm 123^{*}\end{array}$ & $\begin{array}{c}8 \\
13 \\
\pm 3 \\
\pm 3\end{array}$ & $\begin{array}{l}46 \\
\pm 8 \\
73 \\
\pm 17^{*}\end{array}$ & $\begin{array}{l}20 \\
\pm 8 \\
47 \\
\pm 17^{*}\end{array}$ & $\begin{array}{l}3.6 \\
\pm 0.3 \\
6.4 \\
\pm 1.5^{*}\end{array}$ & $\begin{array}{c}46 \\
\pm 8 \\
41 \\
\pm 6\end{array}$ & $\begin{array}{l}8 \\
\pm 3 \\
13 \\
\pm 6^{*}\end{array}$ & $\begin{array}{c}73 \\
\pm 6 \\
38 \\
\pm 6\end{array}$ & $\begin{array}{l}- \\
\begin{array}{l}4.4 \\
\pm 1.4\end{array}\end{array}$ & $\begin{array}{l}61 \\
\pm 6 \\
-\end{array}$ \\
\hline \multicolumn{12}{|c|}{ III: PS } \\
\hline $\begin{array}{l}\text { Rest } \\
\text { Ex }\end{array}$ & $\begin{array}{c}80 \\
\pm 3 \\
152 \\
\pm 6 \\
\end{array}$ & $\begin{array}{c}129 \\
\pm 7 \\
774 \\
\pm 23^{*} \\
\end{array}$ & $\begin{array}{l}6 \\
4^{ \pm 1} \\
\pm 0.1^{*}\end{array}$ & $\begin{array}{c}33 \\
\pm 4 \\
58 \\
\pm 8 \\
\end{array}$ & $\begin{array}{c}16 \\
\pm 4 \\
38 \\
\pm 8\end{array}$ & $\begin{array}{l}4 \\
\pm 0.5 \\
8.4 \\
\pm 8^{*}\end{array}$ & $\begin{array}{l}50 \\
\pm 4 \\
55 \\
\pm 4^{*}\end{array}$ & $\begin{array}{l}8 \\
52 \\
\pm 0.7^{*} \\
\end{array}$ & $\begin{array}{c}72 \\
\pm 2 \\
43 \\
\pm 2 \\
\end{array}$ & $\begin{array}{l}- \\
6.8 \\
\pm 0.4 \\
\end{array}$ & $\begin{array}{l}66 \\
\pm 2 \\
-\end{array}$ \\
\hline \multicolumn{12}{|c|}{$\begin{array}{l}\text { (p values) } \\
\text { Scheffe Procedure for Multiple Comparisons }{ }^{12}\end{array}$} \\
\hline $\begin{array}{l}\text { I vs II } \\
\text { Rest } \\
\text { Ex }\end{array}$ & $\begin{array}{l}\text { NS } \\
\text { NS }\end{array}$ & $\begin{array}{l}\text { NS } \\
\text { NS }\end{array}$ & $\begin{array}{l}<0.05 \\
\text { NS }\end{array}$ & $\begin{array}{l}\text { NS } \\
\text { NS }\end{array}$ & $\begin{array}{l}\text { NS } \\
\text { NS }\end{array}$ & $\begin{array}{l}\text { NS } \\
\text { NS }\end{array}$ & $\begin{array}{l}\text { NS } \\
\text { NS }\end{array}$ & $\begin{array}{l}\text { NS } \\
\text { NS }\end{array}$ & $\begin{array}{l}\text { NS } \\
\text { NS }\end{array}$ & $\overline{\mathrm{NS}}$ & NS \\
\hline $\begin{array}{l}\text { I vs ||I } \\
\text { Rest } \\
\text { Ex } \\
\text { || vs || }\end{array}$ & $\begin{array}{l}\text { NS } \\
\text { NS }\end{array}$ & $\begin{array}{l}\text { NS } \\
\text { NS }\end{array}$ & $\begin{array}{l}\text { NS } \\
<0.01\end{array}$ & $\begin{array}{l}\text { NS } \\
\text { NS }\end{array}$ & $\begin{array}{l}\text { NS } \\
\text { NS }\end{array}$ & $\begin{array}{l}\text { NS } \\
<0.008\end{array}$ & $\begin{array}{l}\text { NS } \\
<0.009\end{array}$ & $\stackrel{\text { NS }}{<0.01}$ & $\begin{array}{l}\text { NS } \\
\text { NS }\end{array}$ & $\overline{<} 0.001$ & NS \\
\hline $\begin{array}{l}\text { II vs III } \\
\text { Rest } \\
\text { Ex }\end{array}$ & $\begin{array}{l}\text { NS } \\
\text { NS }\end{array}$ & $\begin{array}{l}\text { NS } \\
\text { NS }\end{array}$ & $\begin{array}{l}<0.05 \\
<0.01\end{array}$ & $\begin{array}{l}\text { NS } \\
\text { NS }\end{array}$ & $\begin{array}{l}\text { NS } \\
\text { NS }\end{array}$ & $\begin{array}{l}\text { NS } \\
<0.008\end{array}$ & $\begin{array}{l}\text { NS } \\
<0.009\end{array}$ & $\begin{array}{l}\text { NS } \\
<0.02\end{array}$ & $\begin{array}{l}\text { NS } \\
\text { NS }\end{array}$ & $\overline{<0} .001$ & NS \\
\hline
\end{tabular}




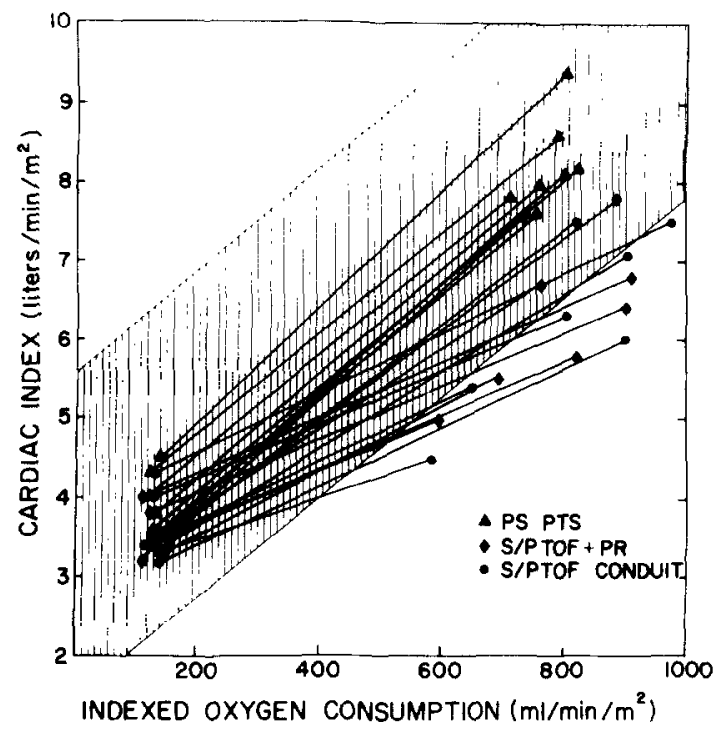

FICURE 1. Relation between cardiac index and indexed oxygen consumption at rest and during exercise in seven patients (PTS) with no pulmonary regurgitation (PR) after repair of tetrad of Fallot (ToF) with a valved conduit (circles); eight patients with moderate pulmonary regurgitation after repair of tetrad of Fallot with an outflow patch (diamonds); and seven nonsurgically treated patients with mild pulmonary stenosis (PS) (triangles). The hatched area represents the normal range. ${ }^{11}$ Values in all but four patients with tetrad of Fallot (three with and one without pulmonary regurgitation) are distinctly below the normal range. $S / P=$ post repair.

outflow tract gradient increased in all patients and there was no significant difference among the three groups. Cardiac index was the same at rest in all three groups, but during exercise it was significantly smaller in both surgically treated groups than in the group with mild pulmonary stenosis $(\mathrm{p}<0.008)$ (Table II).

The relation between the change in oxygen consumption and cardiac index with exercise was abnormal in both surgically treated groups when compared with that in patients with mild pulmonary stenosis or with no heart disease ${ }^{11}$ (Fig. 1). Only 4 of 15 patients with repair had a normal relation between oxygen consumption and cardiac index (3 with [Patients 19, 11 and 15] and 1 without pulmonary insufficiency [Patient 3]). The exercise factor-the ratio of the change in cardiac index to the change in indexed oxygen consumption - was significantly smaller in both groups with repair than in the group with mild pulmonary stenosis $(p<0.001)$.

Stroke index during exercise (Table II): Stroke index was not significantly different among the three groups at rest, but was significantly higher with exercise in the patients with mild pulmonary stenosis $(\mathrm{p}<0.009)$. The pattern of change of stroke index was also different. In the group with mild pulmonary stenosis, stroke index increased during exercise, whereas in both groups with repair stroke index decreased with exercise. In addition, both right ventricular end-diastolic and pulmonary capillary wedge pressures decreased with exercise in the patients with mild pulmonary stenosis, whereas in both

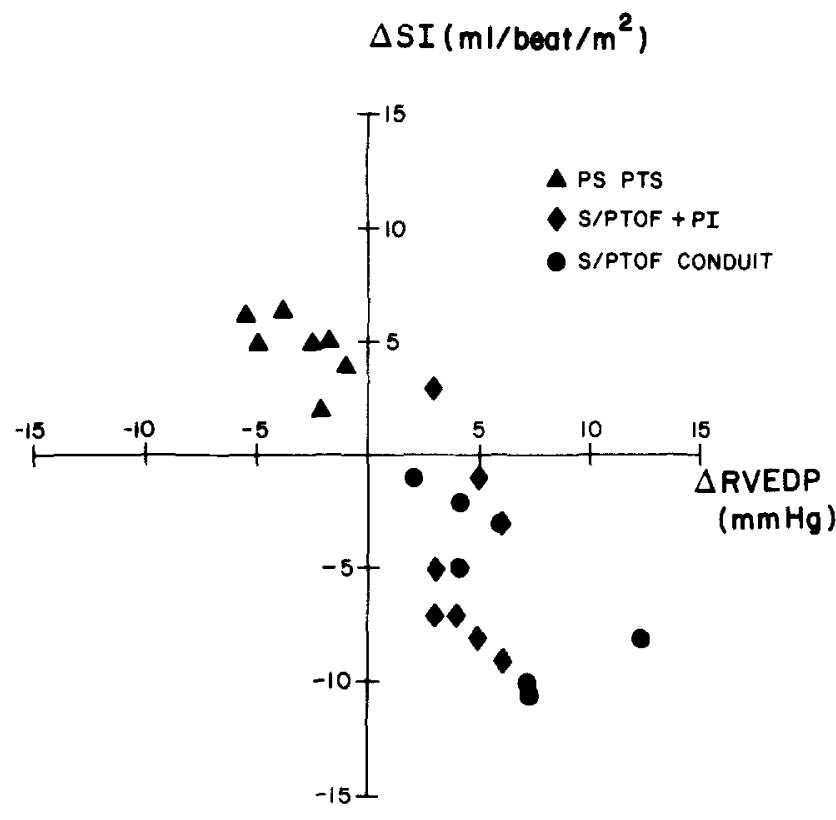

FIGURE 2. Exercise-induced changes in stroke index $(\Delta S \mid)$ and right ventricular end-diastolic pressure ( $\triangle$ RVEDP) in seven patients without pulmonary insufficiency (PI) after repair of tetrad of Fallot (circles); eight patients with moderate pulmonary insufficiency after repair of tetrad of Fallot (dlamonds) and seven nonsurgically treated patients with mild pulmonary stenosis (PS) (triangles). The responses were abnormal in both groups of surgically treated patients.

groups with repair, these pressures increased with exercise. When comparing the changes from rest to exercise of stroke index and either right ventricular enddiastolic or pulmonary capillary wedge pressure, differences among the groups were more apparent. In the patients with mild pulmonary stenosis, stroke index increased during exercise while right ventricular enddiastolic and pulmonary capillary wedge pressures decreased (a normal response); however, in both groups with repaired tetrad of Fallot, stroke index decreased during exercise while both right ventricular end-diastolic and pulmonary capillary wedge pressures increased (an abnormal response) (Fig. 2 and 3).

\section{Discussion}

Abnormal response to exercise after repair of tetralogy of Fallot: Previous evaluations of the exercise hemodynamics after repair of tetrad of Fallot ${ }^{1-6}$ demonstrated that a small number of patients have an impaired cardiovascular response to exercise despite the lack of symptoms and the absence of residual intracardiac shunts. The cause of the impaired response to exercise in these patients is not known, yet some investigators have argued that either exercise-induced right ventricular outflow tract obstruction, ${ }^{1}$ residual pulmonary insufficiency, ${ }^{5}$ right ventricular dysfunction $^{2-4,6}$ or left ventricular dysfunction, ${ }^{6-8}$ or both, may be the cause. In an attempt to clarify the cause of abnormal exercise function in patients with repaired tetrad of Fallot, we compared the hemodynamic response 
to supine exercise in two groups of patients with repaired tetrad of Fallot (one group with and the other without pulmonary regurgitation) with that in a group of patients who had mild pulmonary stenosis. All surgically treated patients underwent repair after early childhood (greater than age 8 years) and had a good hemodynamic repair (no intracardiac shunts and a right ventricular systolic pressure at rest of less than $60 \mathrm{~mm}$ $\mathrm{Hg}$ ). Both surgically treated groups demonstrated deficiencies in cardiac pump function during supine exercise by comparison with patients with pulmonary stenosis (that is, a lower than anticipated cardiac index for the amount of oxygen consumed and a significant decrease in stroke index ${ }^{14,15}$ ). Because all three groups of patients had the same degree of exercise-induced right ventricular outflow tract obstruction, it is unlikely that this obstruction alone is the major cause of the abnormal exercise response observed. In addition, there was no significant difference in the exercise hemodynamics of our patients with and without pulmonary insufficiency. Therefore, it is also unlikely that pulmonary regurgitation is the major cause of the abnormal exercise response observed.

Cause of impaired exercise response: role of increased right ventricular end-diastolic and pulmonary capillary pressures: Because abnormalities in both left and right ventricular function can alter the cardiac response to exercise, we next attempted to evaluate myocardial muscle function by measuring exercise-induced changes in both right and left ventricular end-diastolic pressures. With exercise, the patients with mild pulmonary stenosis exhibited a normal decrease in both right ventricular end-diastolic and pulmonary capillary wedge pressures, whereas both groups of surgically treated patients showed an abnormal increase in both pressures with exercise (Table II). Others ${ }^{3,6}$ have also demonstrated that exercise causes some patients with repaired tetrad of Fallot to have a decrease in stroke index and a concomitant increase in right ventricular end-diastolic and pulmonary wedge pressures.

The increase in right ventricular end-diastolic pressure with exercise probably represents an abnormality of both left and right ventricular compliance. ${ }^{14}$ Myocardial hypertrophy or fibrosis or increased ventricular volume alone or in combination can cause $a b-$ normalities in ventricular compliance. Because the exercise-induced increase in right ventricular end-diastolic and pulmonary capillary wedge pressures were also associated with a significant decrease in stroke volume, the altered ventricular compliance in our patients with repaired tetrad of Fallot can best be explained by the presence of both right and left ventricular myocardial fibrosis in addition to myocardial hypertrophy ${ }^{14}$ (Fig. 2 and 3). Lev et al. ${ }^{16}$ and Krymsky ${ }^{17}$ demonstrated focal fibrosis of the left ventricle and diffuse fibrosis of the right ventricle in patients with tetrad of Fallot. In addition, Jones and Ferrans ${ }^{18}$ suggested that in the patient who is not operated on, the histologic changes in the right ventricular myocardium can progress with time.

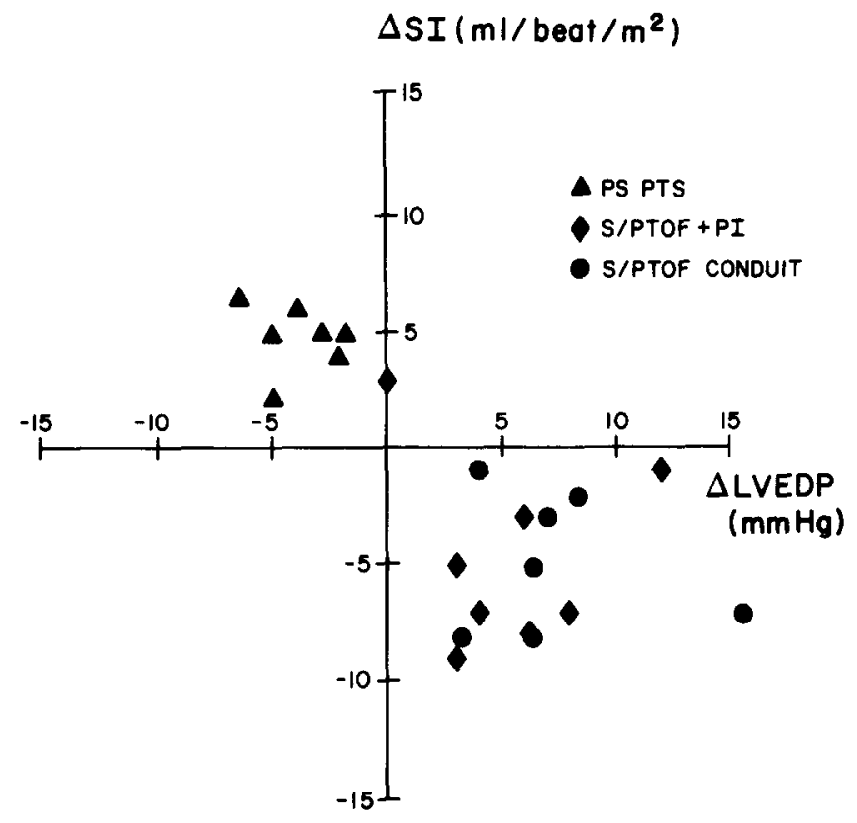

FIGURE 3. Exercise-induced changes in stroke index $(\Delta \mathrm{SI})$ and left ventricular end-diastolic pressure ( $\Delta$ LVEDP) in seven patients without pulmonary insufficiency (PI) after repair of tetrad of Fallot (ToF) (clrcles), eight patients with moderate pulmonary insulficiency after repair of tetrad of Fallot (dlamonds) and seven nonsurgically treated patients with mild pulmonary stenosis (PS) (triangles). The responses were abnormal in both groups of surgically treated patients.

In addition to focal left and diffuse right ventricular fibrosis, other factors may also have contributed to the abnormal myocardial compliance observed in the 15 surgically treated patients. These might include myocardial damage incurred through failure to preserve the ischemic myocardium during cardiac bypass, prolonged length of aortic cross-clamp time and ischemic arrest, failure of regression of right ventricular hypertrophy and the long-term effect of arterial desaturation. ${ }^{8}$

Comparison with previous studies: Our study had a larger number of patients with an impaired cardiovascular response to exercise than that in other studies on exercise hemodynamics after repair of tetrad of Fallot. $^{2,5,6}$ This difference is largely due to the fact that all of our patients were both more than age 8 at the time of their surgical repair and had a severe form of tetrad of Fallot requiring extensive right ventricular outflow tract reconstruction with either a valved conduit or large outflow patch. Borow et al. ${ }^{19}$ observed that ventricular dysfunction was present in patients with tetrad of Fallot repaired at an older age, but not in patients whose repair was performed during infancy. James et $a .^{20}$ also reported that patients who had intracardiac repair of tetrad of Fallot after age 10 appear to have a smaller work capacity than do patients who had repair at an earlier age.

Clinical implications: The long-term significance of the impaired hemodynamic response to exercise in patients with tetrad of Fallot remains to be determined. Six patients in our study had significant ventricular 
arrhythmia induced by treadmill exercise. Gillette et al. ${ }^{21}$ and Wessel et al. ${ }^{22}$ suggested that cardiac dysfunction may be the cause of ventricular arrhythmias in patients after repair of tetrad of Fallot. Garson et al. ${ }^{23}$ also demonstrated that the presence of residual right ventricular hypertension (right ventricular systolic pressure greater than $60 \mathrm{~mm} \mathrm{Hg}$ ) relates to the development of ventricular arrhythmia in patients after repair of tetrad of Fallot.
In the light of our study we recommend that ventricular function during stress become a routine part of the postoperative cardiac catheterization in all patients with tetrad of Fallot, especially in those patients who undergo repair at an older age and have a severe anatomic form of the defect. In addition, any patient who has an impaired cardiac response to supine exercise, even after a good hemodynamic repair, may be at a high risk for the development of ventricular arrhythmia.

\section{References}

1. Epstein SE, Beser GD, Clocstein RE, Rosing DR, Redwood DR, Norrow AG. Hemodynamic abnormalities in response to mild and intense upright exercise following operative correction of an atrial septal defect or tetralogy of Fallot. Circulation 1973;47:106575.

2. Mocellin R, Bastanier C, Hofacker W, Bukhlmeyer K. Exercise performance in children and adolescents after surgical repair of tetralogy of Fallot. Eur J Cardiol 1976;4:367-74.

3. Brlstow JD, Kloster FE, Lees MH, Menashe V, Griswold H, Starr A. Serial cardiac catheterization and exercise hemodynamics after correction of tetralogy of Fallot. Circulation 1970;41:1057-66.

4. Bjarke B. Functional studies in palliated and totally corrected adult patients with tetralogy of Fallot. Scand J Thorac Cardiovasc Surg [Suppl] 1974;16:1-20.

5. Rooing DR, Borer JS, Kent KM, et al. Long-term hemodynamic and electrocardiographic assessment following operative repair of tetralogy of Fallot. Circulation 1978;58:Suppl 1:1-209-17.

6. Finnegan P, Marder R, Patel RG, Abrams LD, Singh SF. Results of total correction of the tetralogy of Fallot long-term hemodynamic ovaluation at rest and during exercise. Br Heart $J$ 1976:38:93442.

7. Rocchinl A, Keane JF, Freed MD, Castaneda AR, Nadas A. Left ventricular function following attempted surgical repair of tetralogy of Fallot. Circulation 1978;57:798-802.

8. Jarmakani J, Graham T, Canent R, Jewett PL. Left heart function in children with tetralogy of Fallot before and after palliative or corrective surgery. Clrculation 1972;46:478-90.

9. Doan AE, Peterson DA, Blackmon JR, Bruce RA. Myocardial ischemia after maximal exercise in healthy men. Am Heart $J$ 1965;69:11-21.

10. Lock JE, Elnzig S, Moller JH. Hemodynamic response to exercise in normal children. Am J Cardiol 1978;41:1278-84

11. Dodge HT, Sandler H, Baller DW, Lond JD. Use of biplane angi- ography for measurement of left ventricular volume in man. Am Heart J 1960;60:762-76.

12. Scheffe H. Analysis of Variance. New York: John Wiley \& Sons, 1959:68-72

13. Lown B, Wolf B. Approach to sudden death from coronary heart disease. Circulation 1971;44:130-42.

14. Moller JH, Rao BNS, Lucus RF Jr. Exercise hemodynamics of pulmonary valvar stenosis. Circulation 1972;40:1018-26.

15. Epetoin SE, Beteor GD, Stampfer M, Robinson BF, Braunwald E. Exercise in patients with heart disease: effects of body position, type and intensity of exercise. Am J Cardiol 1969;23:573-6.

16. Lev M, Rlmoldi HAJ, Rowlat UF. The quantitative anatomy of cyanotic tetralogy of Fallot. Circulation 1964;30:531-8.

17. Krymskl LD. Pathological anatomy of congenital heart disease. Circulation 1965;32:814-27.

18. Jones M, Ferrans V. Myocardial degeneration in congenital heart disease (abstr). Circulation 1976;54:Suppl II:I-229.

19. Borow KM, Green LH, Castaneda AR, Keane JF. Left ventricular dysfunction after repair of tetralogy of Fallot and its relationship to age at surgery. Circulation 1980;61:1150-8.

20. James FW, Kaplan S, Schwartz DC, Chou T, Sandker MJ, Naylor V. Response to exercise in patients after total surgical correction of tetralogy of Fallot. Circulation 1976;54:671-7.

21. Gillette PC, Yeoman MA, Mullins CE, MCNamara DG. Sudden death after repair of tetralogy of Fallot. Electrocardiographic and electrophysiologic abnormalities. Circulation 1977;56:566-71.

22. Wessel HU, Bastanier CK, Paul MH, Berry TE, Cole RB, Muster AJ. Prognostic significant of arrhythmia in tetralogy of Fallot after intracardlac repair. Am J Cardiol 1980;46:843-8.

23. Garson A Jr, Gillette PC, Guigeeell HP, McNamara DG. Stressinduced ventricular arrhythmia after repair of tetralogy of Fallot. Am J Cardiol 1980;46:1006-12. 